\title{
Measurements and Analysis of Secondary User Device Effects on Digital Television Receivers
}

\author{
Timothy R. Newman, ${ }^{1}$ Daniel DePardo, ${ }^{2}$ Alexander M. Wyglinski, ${ }^{3}$ Joseph B. Evans, ${ }^{2}$ \\ Rakesh Rajbanshi, ${ }^{2}$ Victor R. Petty, ${ }^{2}$ Dinesh Datla, ${ }^{1}$ Frederick Weidling, ${ }^{2}$ Paul J. Kolodzy, ${ }^{4}$ \\ Michael J. Marcus, ${ }^{5}$ Gary J. Minden, ${ }^{2}$ and James A. Roberts ${ }^{2}$
}

${ }^{1}$ Electrical and Computer Engineering, Virginia Tech, Blacksburg, VA 24061, USA

${ }^{2}$ ITTC, University of Kansas, Lawrence, KS 66044, USA

${ }^{3}$ Worcester Polytechnic Institute, Worcester, MA 01609, USA

${ }^{4}$ Kolodzy Consulting, P.O. Box 1443, Centreville, VA 20120, USA

${ }^{5}$ Marcus Spectrum Solutions LLC, 8026 Cypress Grove Lane, Cabin John, MD 20818, USA

Correspondence should be addressed to Joseph B. Evans, evans@ittc.ku.edu

Received 7 July 2009; Accepted 12 August 2009

Recommended by K. Subbalakshmi

\begin{abstract}
This article presents results from a study of the potential effects of secondary users operating in unoccupied television spectrum. Television spectrum is known within the wireless communications community as being underutilized, making it a prime candidate for dynamic spectrum access. The proposed use of this open spectrum has prompted questions concerning the quantity of available channel space that could be used without negative impact on consumers who view digital television broadcasts and the viability of secondary use of open channels immediately adjacent to a digital television broadcast channel. In this work, we investigate secondary device operation in the channels directly adjacent to a desired television channel, and the effects upon a selection of consumer digital television (DTV) receivers. Our observations strongly suggest that secondary users could operate "White Space Devices" (WSDs) in unoccupied channel bandwidth directly adjacent to a desired digital television (DTV) channel, with no observable adverse impact upon the reception of the desired channel content.
\end{abstract}

Copyright (C) 2009 Timothy R. Newman et al. This is an open access article distributed under the Creative Commons Attribution License, which permits unrestricted use, distribution, and reproduction in any medium, provided the original work is properly cited.

\section{Introduction}

The growing demand for wireless services and applications shows no sign of slowing down. However, the current command-and-control regulatory structure for licensing spectrum has been unable to cope with the dramatic growth of the wireless industry. This has given rise to an "artificial scarcity" with regard to spectrum, resulting in prices for spectrum licenses becoming so cost prohibitive that many small to medium size businesses are prevented from entering the wireless market. Numerous studies have begun to examine how licensed spectrum is actually used, with the goal of not only rethinking the spectrum licensing regime, but also opening certain underutilized "prime" spectrum to unlicensed and licensed secondary usage. It has been shown that several spectral bands, including the television spectrum, are underutilized [1].

There have been regulatory and legislative efforts to allow new wireless devices access to television (TV) band white space on a per market basis. This approach, referred to as dynamic spectrum access (DSA), allows unlicensed devices to transmit in parts of the spectrum unoccupied by the licensed signals. In June 28, 2006, the Senate Commerce Committee adopted "The Advanced Telecommunications and Opportunity Reform Act of 2006" (S. 2686), which built upon the May 2004 Federal Communications Commission (FCC) Notice of Proposed Rulemaking (NPRM) [2] allowing unlicensed devices to utilize unused spectrum in the TV band. This legislation required the FCC to continue with rule making procedures governing the opening of TV channels 


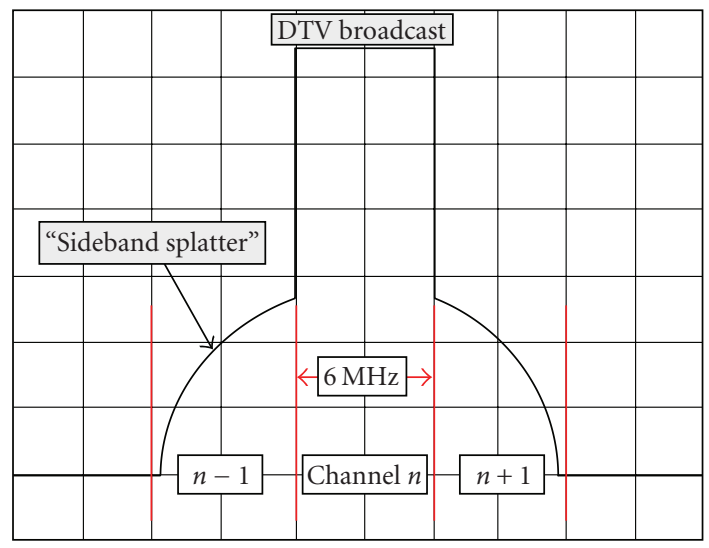

FIgURe 1: Adjacent Channel Interference.

TABLe 1: Adjacent channel measurements.

\begin{tabular}{lccc}
\hline $\begin{array}{l}\text { Channel } \\
\text { Offset }\end{array}$ & $\begin{array}{c}\text { Receiver 1 } \\
\text { (set top) }\end{array}$ & $\begin{array}{c}\text { Receiver 2 } \\
\text { (LCD DTV) }\end{array}$ & $\begin{array}{c}\text { Receiver 3 } \\
\text { (set top) }\end{array}$ \\
\hline-1 & $-34 \mathrm{dBm}$ & $-30 \mathrm{dBm}$ & $-29 \mathrm{dBm}$ \\
-1.5 & $-24 \mathrm{dBm}$ & $-18 \mathrm{dBm}$ & $-26 \mathrm{dBm}$ \\
-2 & $-15 \mathrm{dBm}$ & $-16 \mathrm{dBm}$ & $-22 \mathrm{dBm}$ \\
-6 & N/A & $-15 \mathrm{dBm}$ & N/A \\
-8 & N/A & $-14 \mathrm{dBm}$ & N/A \\
\hline
\end{tabular}

TABLE 2: Co-channel desired/undesired ratio measurements.

\begin{tabular}{lccc}
\hline ATSC & $\begin{array}{c}\text { Receiver } 1 \\
(\text { set top })\end{array}$ & $\begin{array}{c}\text { Receiver } 2 \\
(\text { LCD })\end{array}$ & $\begin{array}{c}\text { Receiver 3 } \\
\text { (set top })\end{array}$ \\
\hline Threshold & 20 & 15 & 17 \\
& $(-102 \mathrm{dBm})$ & $(-96 \mathrm{dBm})$ & $(-97 \mathrm{dBm})$ \\
$-68 \mathrm{dBm}$ & 13 & 11 & 12 \\
& $(-81 \mathrm{dBm})$ & $(-79 \mathrm{dBm})$ & $(-80 \mathrm{dBm})$ \\
$-61 \mathrm{dBm}$ & 12 & 11 & 11 \\
& $(-73 \mathrm{dBm})$ & $(-72 \mathrm{dBm})$ & $(-72 \mathrm{dBm})$ \\
\hline
\end{tabular}

2-51 (54 MHz-698 MHz) for use by wireless broadband services and other DSA-enabled devices. The FCC proposal also includes the reallocation of TV channels 52-69 $(698 \mathrm{MHz}$ to $806 \mathrm{MHz}$ ) to public safety communications as well as for auction. The NPRM specifies that any devices certified to use TV spectrum white spaces should employ either agile or cognitive radio technology in a dynamic spectrum access configuration, such that these devices would not interfere with primary rights holders, for example, television broadcasters. Further legislative direction was provided in the Balanced Budget Act of 1997 (H.R.2015), Title III - Communications and Spectrum Allocation Provisions [15]. In November 3, 2008, FCC commissioners voted unanimously to officially approve the use of these bands by white space devices (WSDs).
In a DSA approach, the "secondary" users must not cause any "harmful interference" to the primary users as well as the other secondary users sharing the same portion of the spectrum. The definition of "harmful" is outside the scope of this article, but is typically associated with the affected applications and their hardware characteristics. Since primary users hold exclusive rights to the spectrum, it is not their responsibility to mitigate any additional interference caused by secondary device operation. These devices will need to periodically sense spectrum in order to detect primary and secondary user transmissions, and have the capability of adapting to the varying spectrum conditions for mutual interference avoidance [3]. Groups representing traditional incumbent users, such as television broadcasters, feel that opening up the white space to DSAenabled secondary users will cause unneeded interference and disrupt communications for television broadcasters and public safety communication systems. Recently the National Association of Broadcasters and Association for Maximum Service Television went so far as to sue the FCC over its decision to authorize the operation of WSDs in the unused television channels. The availability of the underutilized television spectrum is not disputed. However, there are two remaining technical issues that the regulatory and business communities must address. The regulatory community must determine the technical rules that devices must use when accessing this spectrum in order to prevent harmful interference to the primary devices (i.e. DTV receivers). Additionally, the device manufacturing community must determine if cost effective devices can be created that meet the technical rules for operation.

The technical rules that are of particular interest to the FCC involve device in-band and out-of-band emissions (OOBEs). The device manufacturers must comply with these rules through the selection of appropriate modulation, amplifier, and filter characteristics in both the transmitter and receiver chains of WSDs. The expected RF environment also has a direct impact on the receiver characteristics and thus must be well understood.

In this effort, we present a feasibility study of devices performing DSA in underutilized television bands when television signals are present. The study is divided into two parts. In the first part, the impact of transmissions on the video quality of digital television signals is determined for several scenarios. This will provide the basis in determining the emission levels that can be tolerated by DTV receivers. In the second part, we focus on adjacent channel interference, and measure the affects of a single adjacent channel secondary transmission on a selection of DTV receivers.

\section{Dynamic Spectrum Access Background}

Substantial research efforts have been aimed at the utilization of vacant portions of FCC allocated television spectrum using DSA techniques. IEEE 802.22 is a wireless standard that focuses on reuse of the vacant TV spectrum without causing any harmful interference to the primary users [4]. Some of the important issues that have been addressed include the 


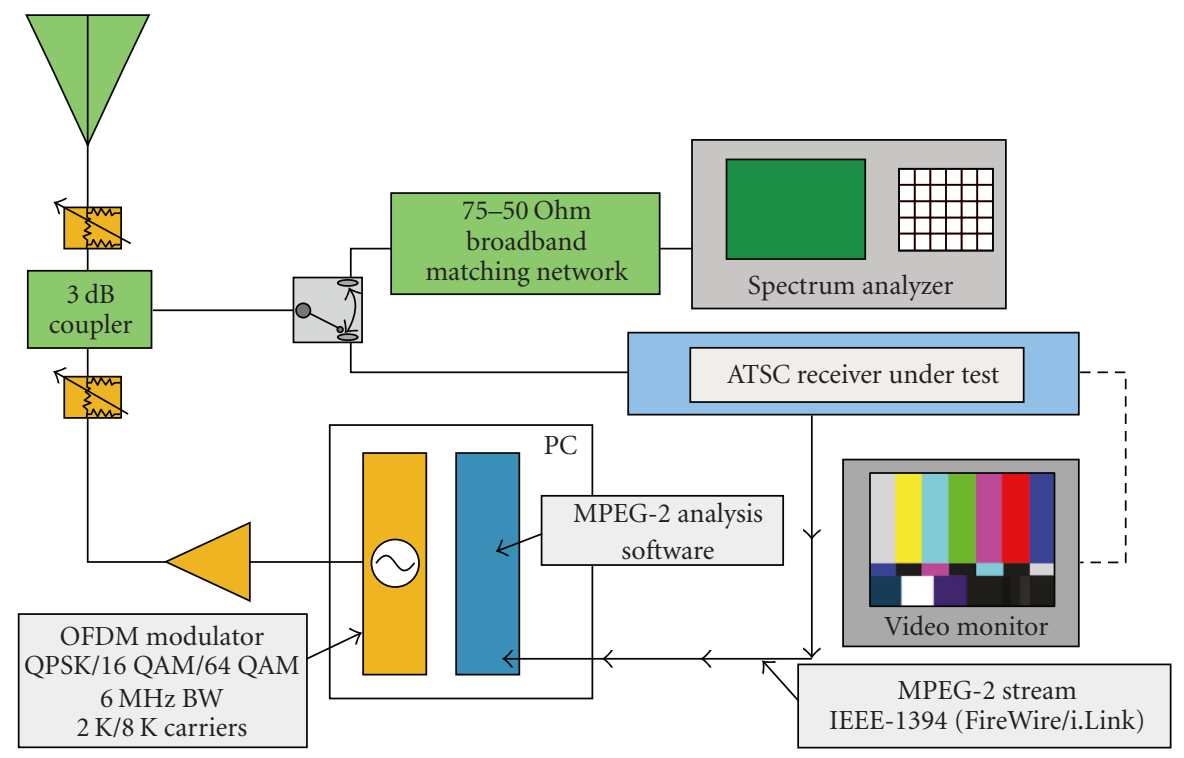

Figure 2: KU White Space Device Emulator and Testbed (KUWSDET).

feature detection of TV signals [5], collaborative sensing for improved detection capabilities [6], detection of the presence of receivers in the vicinity of a secondary device [7], and effective methods for unoccupied TV spectrum access [8]. Our previous work explored the feasibility of secondary user communication from the side of the secondary users [9].

Although it has been demonstrated that DSA methods are effective in avoiding harmful interference to television receivers, there is still debate regarding whether devices can operate in underutilized spectrum without simultaneously causing interference. There are many who claim that WSDs will cause harmful interference to primary users [10], while others argue that DSA can be done in a transparent manner [11] and can be safely implemented using the latest radio technology communications techniques [12]. Proponents of the DSA approach have investigated the use of open television spectrum for several reasons. First, there is a substantial amount of unused spectrum available for DSA. Furthermore, the propagation properties in these frequency ranges, such as low propagation attenuation, are beneficial for long range, mobile, and non-line-of-sight (NLOS) communications [8]. Finally, the fixed channel allocations result in deterministic usage patterns that are favorable for accurate spectrum sensing [13].

There are several challenges that must be addressed in order to enable white space device operation in open TV spectrum. The presence of strong TV signals near the secondary user can lead to the generation of spurious signals, intermodulation products, and saturation effects [14]. These problems might occur at the transmission source, at the DTV receiver, or at the secondary-use receiver. In addition, the secondary device could potentially cause interference to primary users if the spectrum sensing mechanism of the device fails to identify the presence of primary users, or if there is significant out-of-band power leakage from secondary transmissions into the primary user channels.

In previous studies, we presented related results concerning on the impact of TV transmissions on secondary users at varying distances from a transmission tower, and we also provided results that indicated typical current generation consumer DTV receivers were capable of error-free reception of adjacent channel DTV broadcasts. These results, while not comprehensive, provide incentive to further explore the interference relationships between secondary users and DTV receivers.

In this study, we provide a brief review of our secondary user interference feasibility analysis and expand upon the results by focusing on adjacent channel DTV interference. An undesired interfering signal, transmitted in a channel adjacent to a desired signal channel, can introduce thirdorder intermodulation $\left(\mathrm{IM}_{3}\right)$ products generated by transmitter nonlinearities into the desired channel bandwidth, resulting in interference to the desired channel content. In the case of a DTV broadcast, the noise-like characteristics of an 8VSB-modulated digital television signal create $\mathrm{IM}_{3}$ products with the same noise-like properties. These products are often referred to as "sideband splatter" or "shoulders" and result in what is essentially co-channel interference to other signals occupying directly adjacent channels, as illustrated in Figure 1. The threshold for harmful interference (interference levels that impact the operation of the DTV receivers to such an extent that the signal content is severely degraded) varies considerably, and is dependent upon the technical characteristics of the TV receiver and the secondary user device. Therefore, standardized procedures for testing the interference-limiting capabilities of devices should be devised for various spectrum environments and scenarios. Ideally, these techniques and procedures would be based 

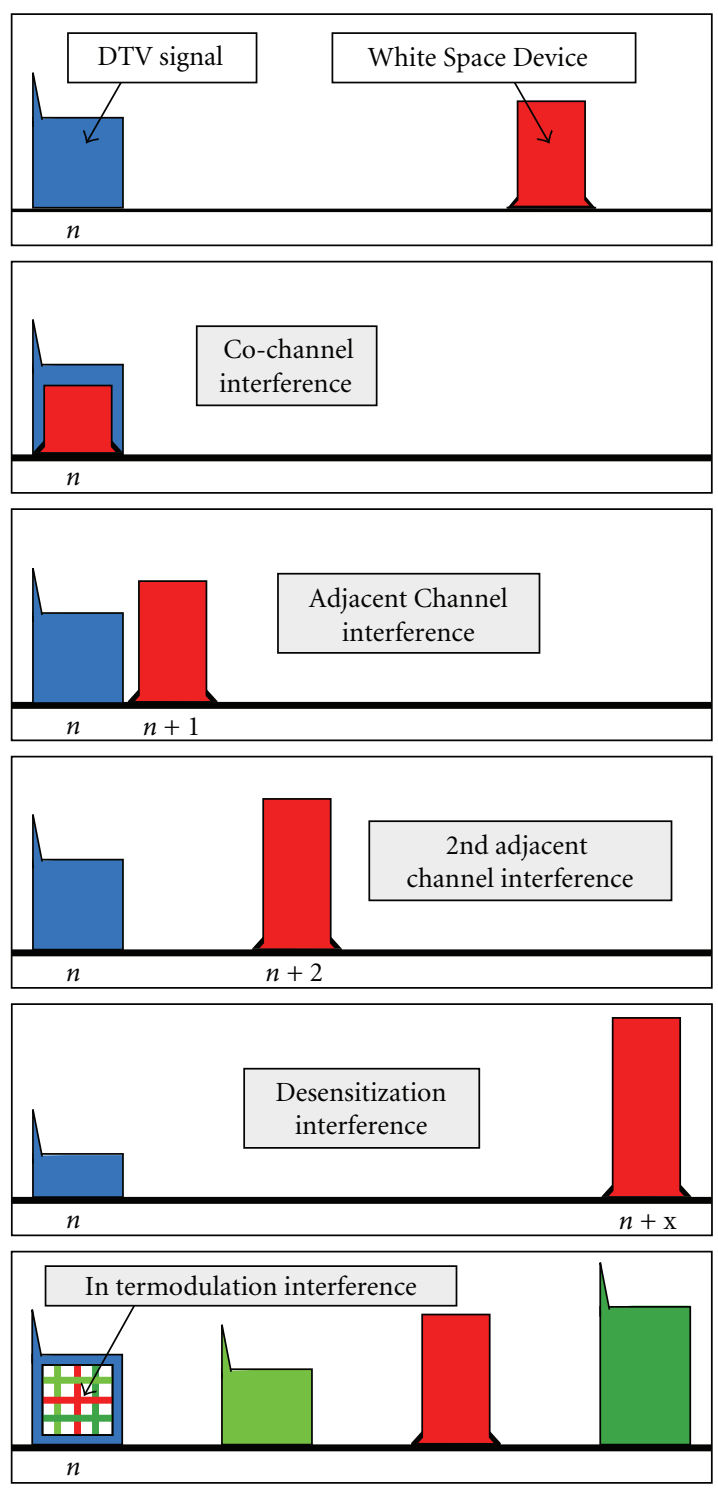

FIgURE 3: Types of potential WSD interference to DTV signals.

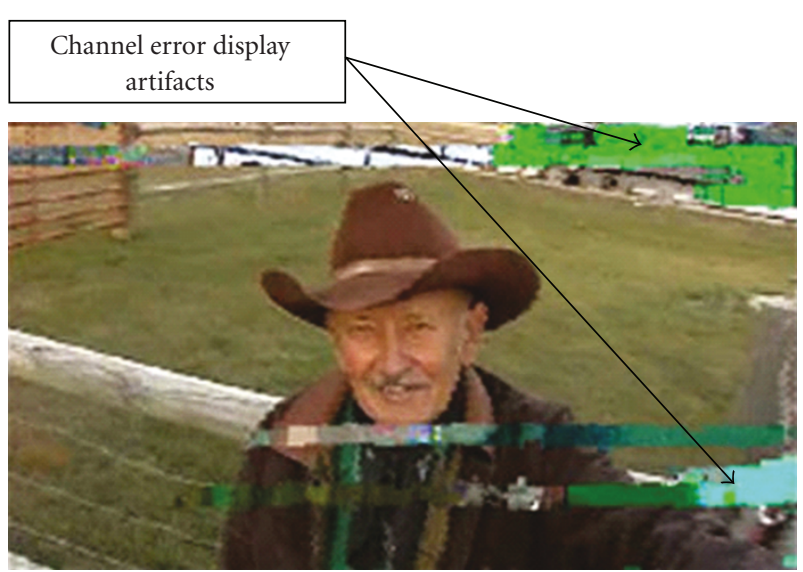

FIGURE 4: Displayed effects of DTV channel errors. upon input from both the academic community and primary rights holders [16].

An investigation studying the operation of public safety transmissions across television spectrum, when both digital and analog television signals were present, has been conducted [17]. Although several insights were obtained regarding the interaction between licensed and unlicensed transmissions, the investigation did not quantify the impact on the video quality of the television signal nor was there an analysis of transmitter nonlinearities.

\section{Viability of DTV Coexisting with Cognitive Radios}

3.1. KU White Space Device Emulator and Testbed. The KU White Space Device Emulator and Testbed (KUWSDET), shown in Figure 2, was initially configured to simulate white space devices operating in the $54 \mathrm{MHz}$ to $806 \mathrm{MHz}$ frequency range using OFDM modulation. WSD emulation was accomplished using a desktop computer equipped with a PCI form factor modulator, which was capable of QPSK, 16 QAM, and 64 QAM, using 2000 or 8000 carriers, and various code rates and guard intervals, with a $6 \mathrm{MHz}$ channel bandwidth. The RF output level can be software controlled over a $31.5 \mathrm{~dB}$ range. Additional RF amplification and step attenuation were inserted into the WSD emulator transmit chain as required in support of specific test parameters. The WSD output and the feed from a roof-mounted consumer grade directional TV antenna were fed into a $3 \mathrm{~dB}$ coupler, and the combined output was switched between a spectrum analyzer and the DTV receiver under test.

In the case of DTV receivers equipped with IEEE-1394 (FireWire/i.Link) output, the KUWSDET has the additional capability of MPEG-2 transport stream statistics analysis, which provides more precise DTV channel performance testing. Tests to date have focused on the effects of WSD transmissions on consumer grade DTV receivers.

3.2. Types of Interference. When wireless transmissions operate in close proximity to each other in the frequency domain, there exists the potential for these signals to interact. This interaction can negatively impact the ability of a receiver to perfectly recover the desired signal. By characterizing the spectral characteristics of the signals located within a frequency range of interest, it is possible to classify the type of interference expected at the receiver. Five types of interference that could exist between a primary DTV signal and a secondary transmission in a dynamic spectrum access network are shown in Figure 3.

The differences between each of these types of interference are based on the relative spacing between the two transmissions, and their relative transmission power levels. For instance, when the DTV signal spectrum is located at channel $n$, and the secondary transmission is also located at the same channel, this is referred to co-channel interference. In this scenario, the desired DTV channel would be severely corrupted by secondary device operation due to its inability to resolve the two signals. Another type of interference can occur if the secondary signal is located in an adjacent 


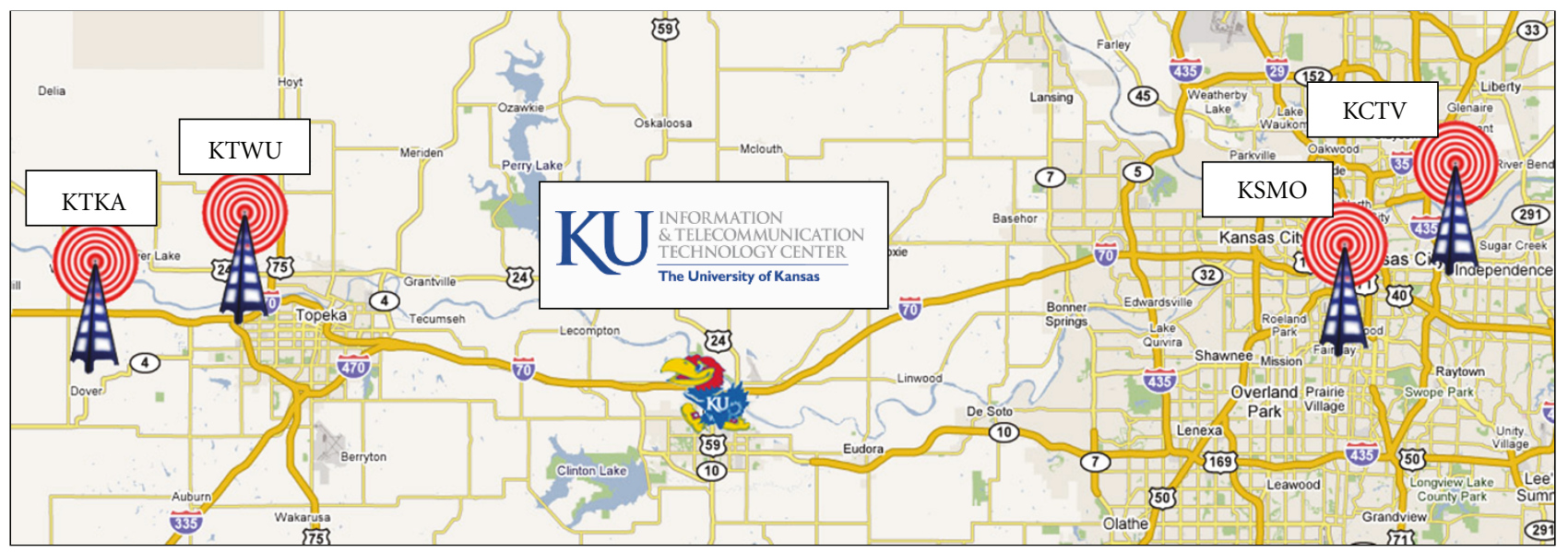

\begin{tabular}{|c|c|c|c|}
\hline & Channel/frequency & $\begin{array}{c}\text { Effective } \\
\text { radiated power }\end{array}$ & $\begin{array}{c}\text { Antenna height above } \\
\text { average terrain }\end{array}$ \\
\hline KTWU-DT & CH $23 / 524-530 \mathrm{MHz}$ & $960 \mathrm{~kW}$ & 281 meters \\
\hline KCTV-DT & $\mathrm{CH} 24 / 530-536 \mathrm{MHz}$ & $1000 \mathrm{~kW}$ & 319 meters \\
\hline KSMO-DT & $\mathrm{CH} 47 / 668-674 \mathrm{MHz}$ & $1000 \mathrm{~kW}$ & 356 meters \\
\hline KTKA-DT & $\mathrm{CH} 48 / 674-680 \mathrm{MHz}$ & $55 \mathrm{~kW}$ & 451 meters \\
\hline
\end{tabular}

FIGURE 5: Adjacent channel DTV broadcast reception in Lawrence, KS.

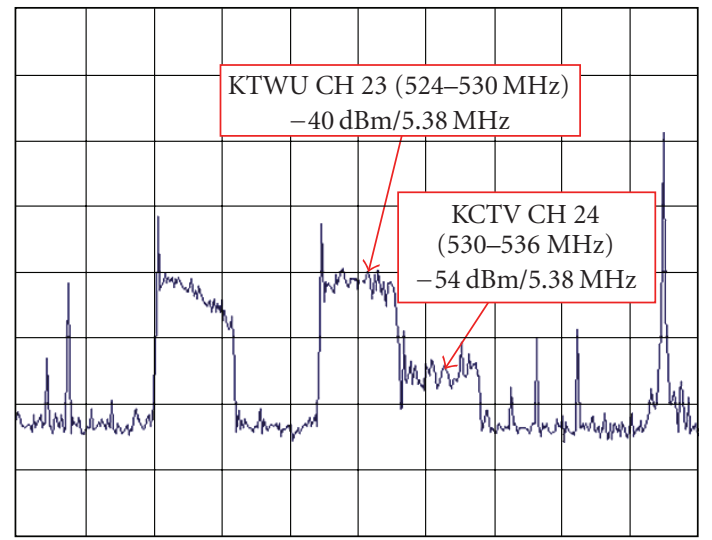

FIgURE 6: KTWU and KCTV Adjacent channel broadcasts.

channel, such as channel $n+1$. In this case, the DTV signal may experience adjacent channel interference from the secondary signal since the transmitted spectrum of the latter may not be totally confined to its allocated band. Note that as the amplitude level of the secondary transmission is increased, so does the amount of out-of-band energy that could interfere with the DTV signal.

If the secondary signal is located further away from the DTV signal, such as the second adjacent channel, the impact of adjacent channel interference is substantially reduced, relative to secondary signals operating closer to the DTV signal, given the same power levels. However, if the power level of the secondary signal is increased, it is possible that out-of-band signal energy may interfere with the DTV signal.
In fact, when the secondary signal is substantially stronger than the DTV signal and is located within the geographical vicinity of a desired frequency, desensitization interference can potentially occur. In this scenario, the secondary signal overloads the receiver, inhibiting its ability to fully recover the desired DTV signal.

Receiver intermodulation interference occurs when two or more signals are present within the same frequency range, and are mixed in a receiver $\mathrm{RF}$ amplifier or mixer stage during nonlinear operation, producing a signal that interferes with a desired signal. Consequently, these receivergenerated signals could prevent the display of the content of a desired DTV channel.

The visible effects of DTV receiver interference can range from mild error artifacts to complete loss of channel content. Figure 4 is an example of moderate display errors.

\subsection{Preliminary DTV Adjacent Broadcast Channel Observa-} tions. As previously discussed, television broadcasters have expressed the concern that secondary use of open spectrum immediately adjacent to an operational digital television channel could create interference for viewers of the DTV channel content. It is interesting to note that despite the best efforts of the FCC to allocate adjacent channel frequencies to transmitters with sufficient geographic separation, it is not particularly unusual for viewers to be located in areas where television markets overlap, allowing adjacent broadcast DTV channel situations to occur.

The Information and Telecommunications Technology Center (ITTC) at the University of Kansas is located approximately halfway between Kansas City and Topeka, with access 


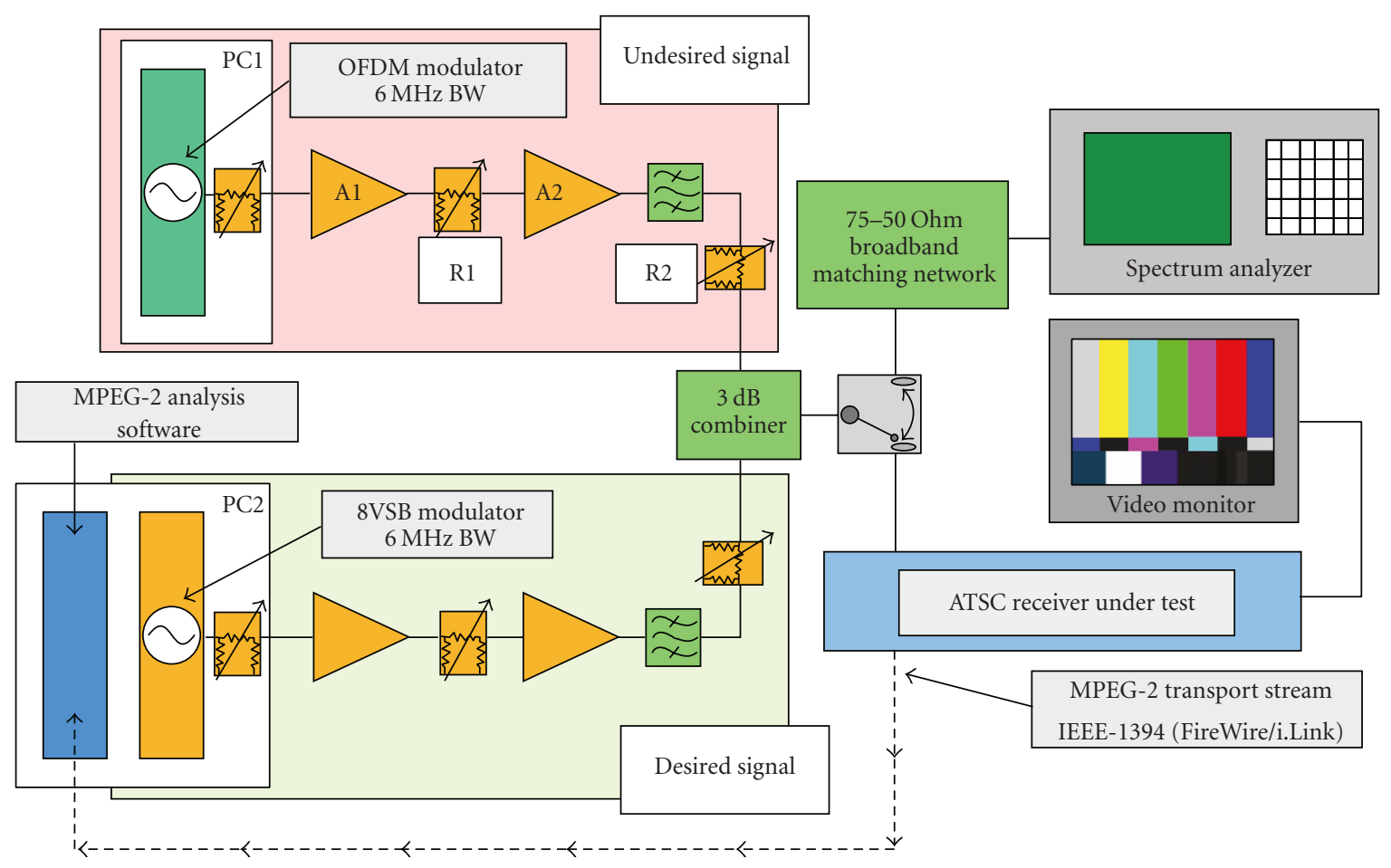

FIGURE 7: KU White Space Device Emulator and Testbed (KUWSDET) provides a controlled environment for observing the effects of nonlinear operation.

to off-the-air DTV content from both media markets, as shown in Figure 5. Two separate instances of adjacent DTV channel pairs can be received at this location, and tests have demonstrated that a selection of consumer DTV receivers are capable of receiving and properly displaying the content of all four channels.

The KTWU transmitter in Topeka, KS, USA which broadcasts on channel $23(524-530 \mathrm{MHz})$, and the KCTV facility in Kansas City, MO, USA broadcasting on channel 24 $(530-536 \mathrm{MHz})$ are the first pair of adjacent DTV channels observed, illustrated in Figure 6. It should be noted that while FCC TV channel allocation bandwidth is $6 \mathrm{MHz}$, the 8 -VSB DTV signal-3 dB bandwidth is $5.38 \mathrm{MHz}$. Content from both channels was displayed during a live demonstration to FCC Commissioner Michael Copps during a visit to ITTC using an unexceptional consumer LCD DTV. Our observations suggest that open adjacent channel bandwidth could also be used for other applications. In the following sections, we actively explore this possibility by generating simulated WSD signals on channels adjacent to DTV transmissions and observing the effects.

\section{Measurements of TV Band White Space Devices and Digital Receivers}

Initial experiments revealed that a relatively high WSD channel power level is required before the output negatively impacts a DTV test receiver. Some preliminary adjacent channel measurements are illustrated in Table 1. Shown are the WSD transmitter levels (in $\mathrm{dBm} / 6 \mathrm{MHz} \mathrm{BW}$ ) required to cause visible impairments to the DTV reception when the received DTV signal is $-61 \mathrm{dBm}$.

Preliminary co-channel measurements are shown in Table 2. The measurements listed are the co-channel desired/undesired $(\mathrm{D} / \mathrm{U})$ ratios required to cause visible impairments to the DTV reception. Note that there is not yet a standard for D/U for non-TV (ATSC/NTSC) signals.

The preliminary experimental results from a limited number of test receivers indicate that the proposed U$\mathrm{D}$ operation in the television band can be accomplished without significant impact upon DTV receivers in the vicinity. Experiments are ongoing and will be thoroughly reported in future publication submissions.

\section{Secondary User Intermodulation Product Analysis}

5.1. Intermodulation Measurement System. As DTV systems have replaced analog TV equipment, television broadcast professionals have found the need to develop new system performance measurement methods and terminology. Enhancements to the traditional third-order intermodulation description for analog signals have been detailed in the article "Interference Mitigation for Improved DTV Reception" [18], where the authors encourage the addition 


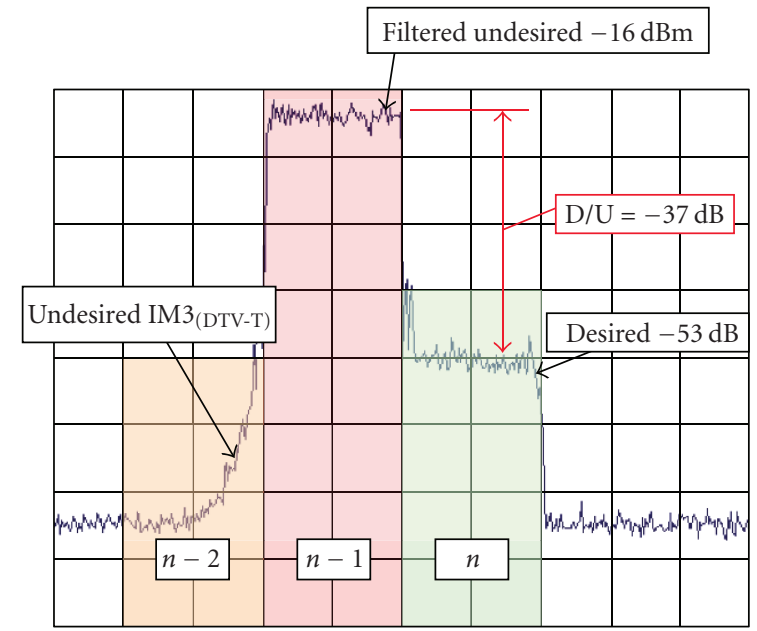

(a)

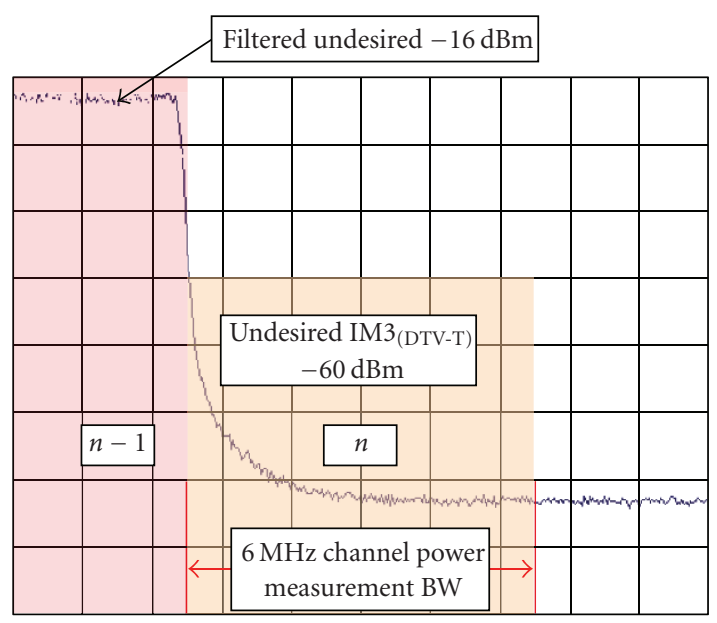

(c)

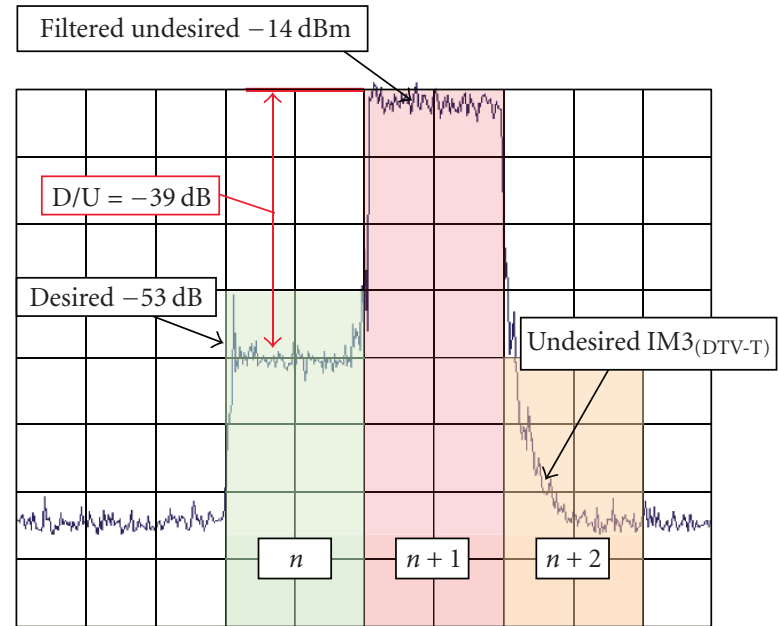

(b)

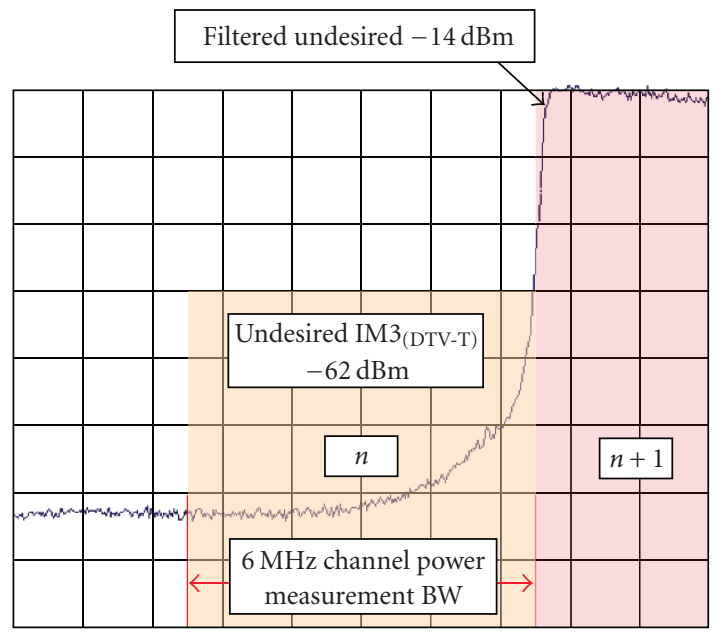

(d)

Figure 8: (a) $n=-53 \mathrm{dBm}$; undesired signal at $n-1$; minimum $\operatorname{IM}_{3(\mathrm{DTV}-\mathrm{T})}$ configuration (b) $n=-53 \mathrm{dBm}$; undesired signal at $n+1$; minimum $\mathrm{IM}_{3(\mathrm{DTV}-\mathrm{T})}$ configuration (c) $\mathrm{IM}_{3(\mathrm{DTV}-\mathrm{T})}$ level present in desired channel $n$. undesired signal at $\mathrm{n}-1$; Minimum IM 3 (DTV-T) Configuration. (d) $\mathrm{IM}_{3 \text { (DTV-T) }}$ Level Present in Desired Channel $n$. Undesired Signal at $n+1$; Minimum IM (DTV-T) $_{\text {Configuration. }}$

of new technical terms to describe DTV transmitter and receiver characteristics.

The proposed "DTV third-order intermodulation product" $\mathrm{IM}_{3 \text { (DTV), }}$, "third-order DTV Intercept Point" IP 3(DTV) $_{\text {, }}$ "DTV Transmitter-generated intermodulation product" $\mathrm{IM}_{3 \text { (DTV-T) }}$, and "DTV Receiver-generated intermodulation product" IM $_{3 \text { (DTV-R) }}$ parameters offer refinements to the generic $\mathrm{IM}_{3}$ and $\mathrm{IP}_{3}$ terms and encourage more specific analysis of the origins of DTV intermodulation interference. The single interferer adjacent channel measurements contained in this article are presented using the techniques and terminology described in the above-mentioned article.

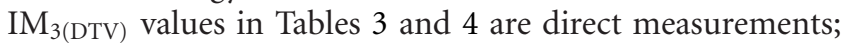
$\mathrm{IP}_{3(\mathrm{DTV})}$ values were calculated using

$$
\mathrm{IP}_{3(\mathrm{DTV})}=\frac{\mathrm{U}+\left(\mathrm{U}-\mathrm{IM}_{3(\mathrm{DTV})}\right)}{2} .
$$

In order to have a controlled environment for testing and analysis we enhanced the capabilities of the KUWSDET with ATSC 8VSB signal generation capability, which was used to create test DTV signals at desired channel locations, supplementing the use of off-the-air broadcast signals. ATSC 8VSB emulation was accomplished using a modestly priced PCI form factor digital modulator and RF frequency synthesizer similar to the hardware used to generate OFDM signals. The $8 \mathrm{VSB}$ and OFDM systems are housed in separate desktop computer cases; modulated test signals are generated using transport stream content stored on hard drives in each computer. Off-air digital broadcast signals are also available for experiments via a directional rooftop-mounted antenna. The KUWSDET is capable of accommodating a variety of experimental scenarios through frequency agility, and flexible configuration of RF amplifier gain blocks, 


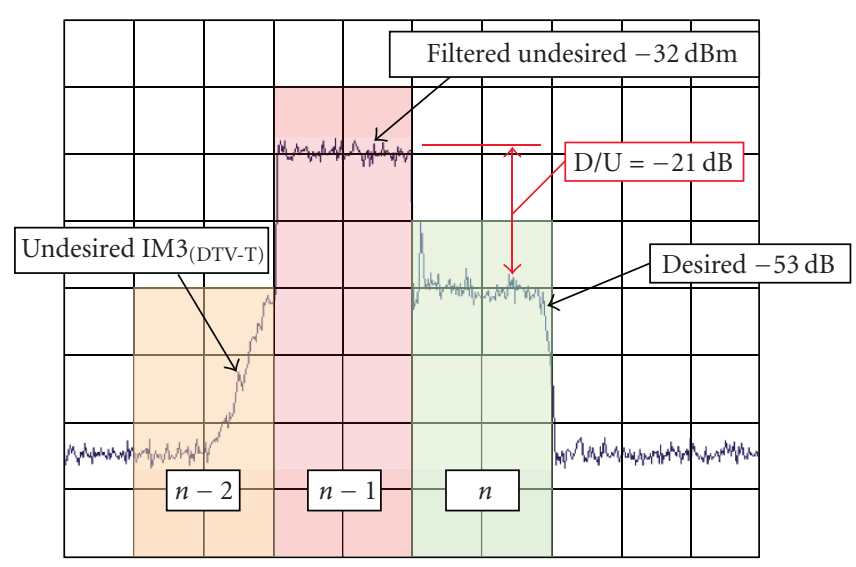

(a)

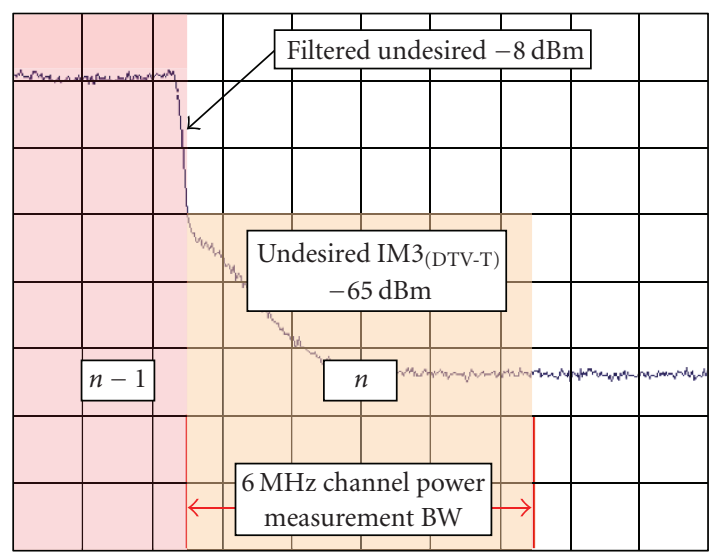

(c)

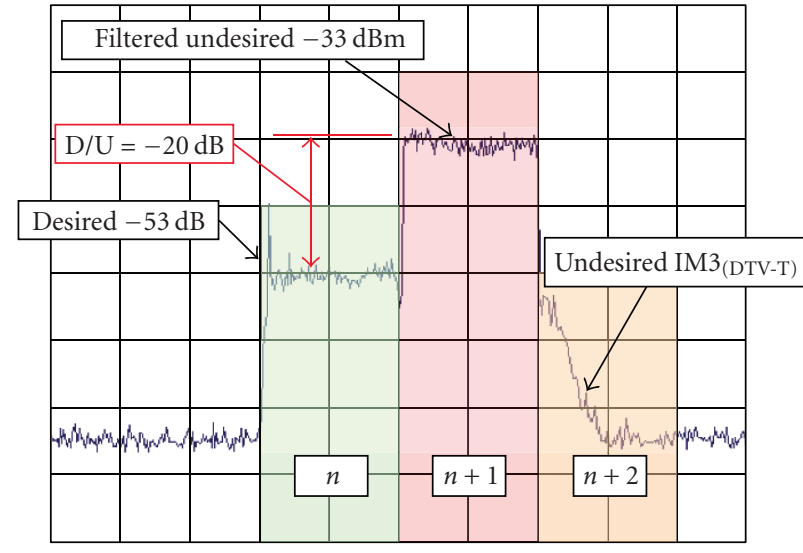

(b)

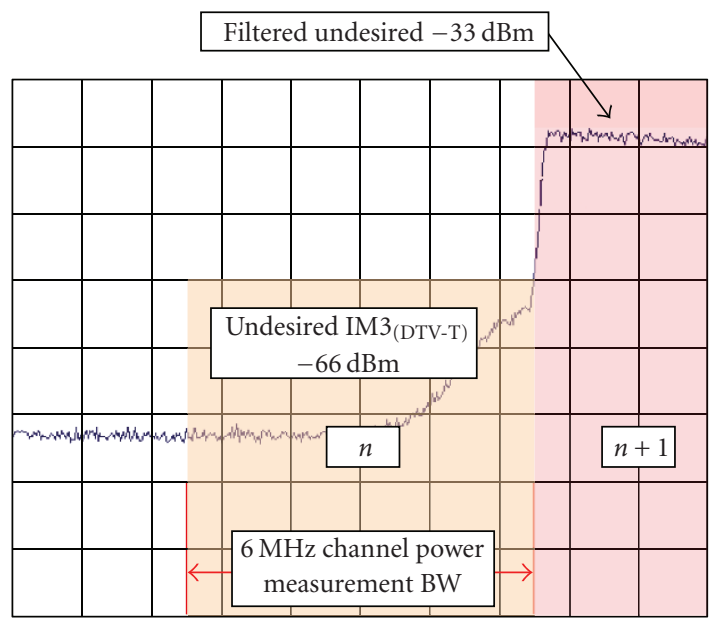

(d)

FIGURE 9: (a) $n=-53 \mathrm{dBm}$; undesired signal at $n-1$; significant $\operatorname{IM}_{3 \text { (DTV-T) }}$ configuration (b) $n=-53 \mathrm{dBm}$; undesired signal at $n+1$; significant configuration (c) $\mathrm{IM}_{3(\mathrm{DTV}-\mathrm{T})}$ level present in desired channel $n$. undesired signal at $n-1$; significant IM $\mathrm{I}_{3 \text { (DTV-T) }}$ configuration. (d) $\mathrm{IM}_{3(\mathrm{DTV}-\mathrm{T})}$ level present in desired channel $n$. Undesired signal at $n+1$; significant $\mathrm{IM}_{3(\mathrm{DTV}-\mathrm{T})}$ configuration.

filters, step attenuators, switches, and power combiners. The configuration used for the $\mathrm{IM}_{3(\mathrm{DTV}-\mathrm{T})}$ measurements presented here is shown in Figure 7.

Nonlinear characteristics of the RF power amplifier, labeled A2 in Figure 7, were used to create IM 3 (DTV-T) interference. The undesired signal $\mathrm{IM}_{3 \text { (DTV-T) }}$ interference level present at the receiver under test input was determined by the input level to A2. The degree to which A2 was driven into nonlinear operation was controlled using the step attenuator labeled R1, while the value of the step attenuator labeled R2 determined the final undesired signal RF channel power level. Single interferer DTV receiver tests were conducted in the upper and lower adjacent channels to a desired DTV signal at two intermodulation interference levels. R1 was used to adjust the Undesired Signal for maximum RF channel power with the minimum $\mathrm{IM}_{3 \text { (DTV-T) }}$ interference present in the adjacent desired channel, and maximum RF channel power with very significant levels of $\mathrm{IM}_{3(\mathrm{DTV}-\mathrm{T})}$.
5.2. Observations. Receivers were first tested using a desired channel power level of $-53 \mathrm{dBm}$ measured in a $6 \mathrm{MHz}$ bandwidth. Channel $31(572-578 \mathrm{MHz})$ was selected as the desired frequency, and the ATSC signal was created using the KUWSDET 8VSB modulator and a looping HDTV MPEG-2 transport stream. The adjacent channel undesired signal was generated using the testbed OFDM-modulator and a looping transport stream. The filtered undesired signal level was configured to generate the minimum level of IM $_{3(\mathrm{DTV}-\mathrm{T})}$ interference while maintaining operation within the region of the $1 \mathrm{~dB}$ compression point $(\mathrm{P} 1 \mathrm{~dB})$ of amplifier $\mathrm{A} 2$. The adjacent channel undesired signal levels required to degrade the $-53 \mathrm{dBm}$ desired channel to TOV are indicated in Table 3(a). Example data from the measurement technique reference [18] is also included for comparison purposes. Spectrum plots representative of a selection of Table 1 measurements are contained in Figures 8(a)-8(d). The DTV receivers were then tested using a filtered undesired signal configured to 


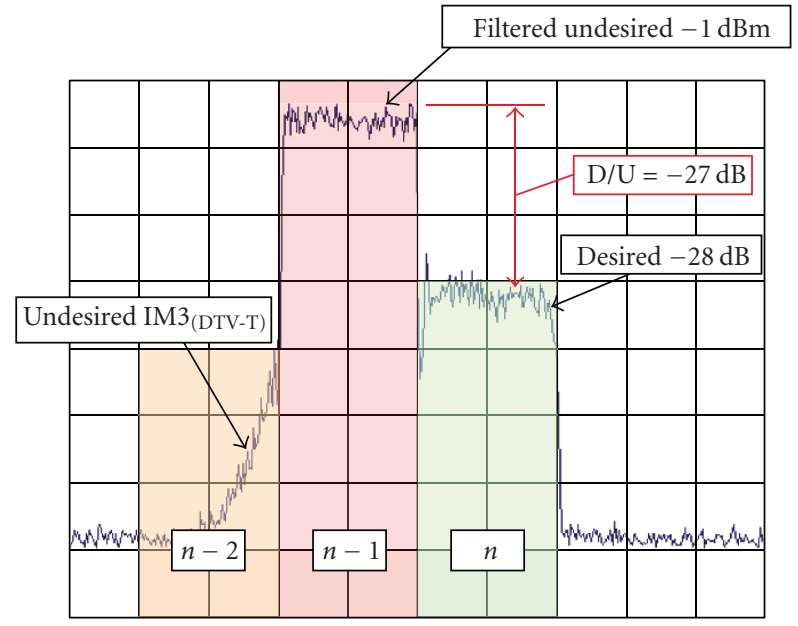

(a)

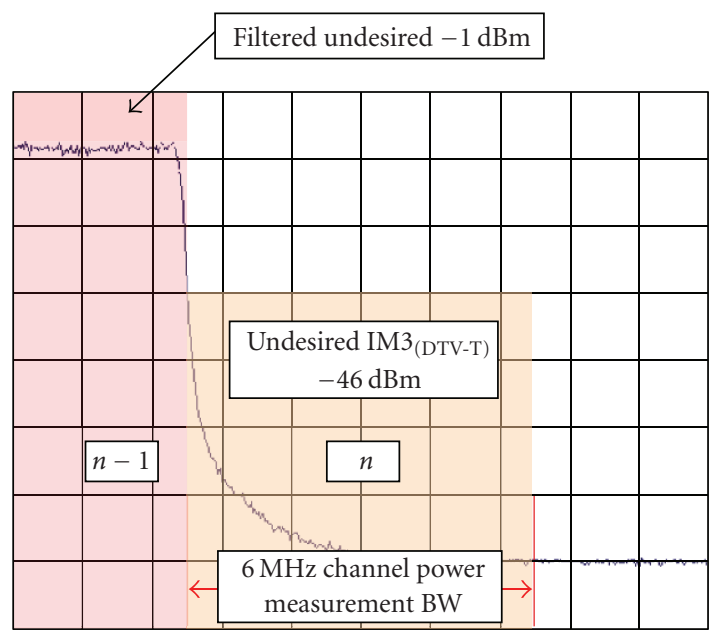

(c)

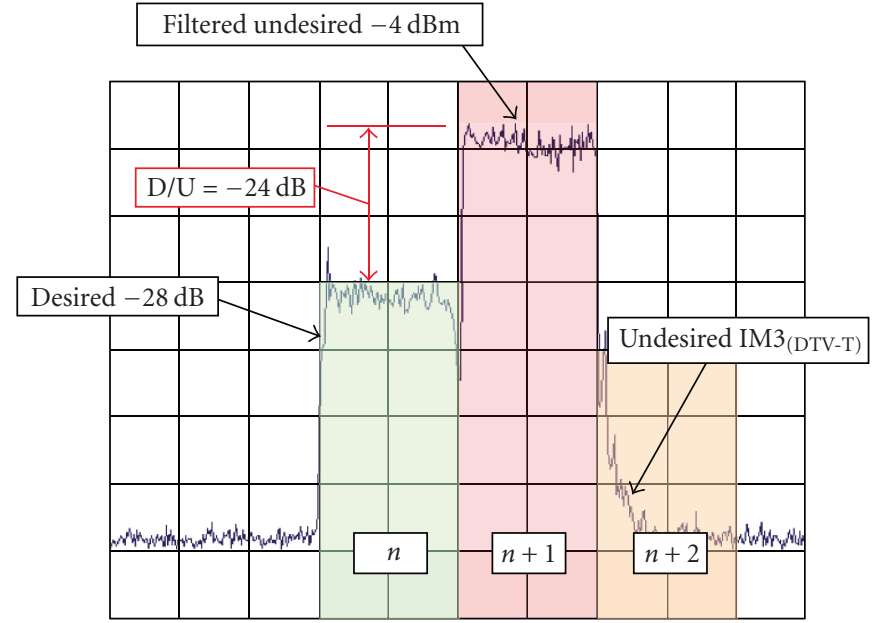

(b)

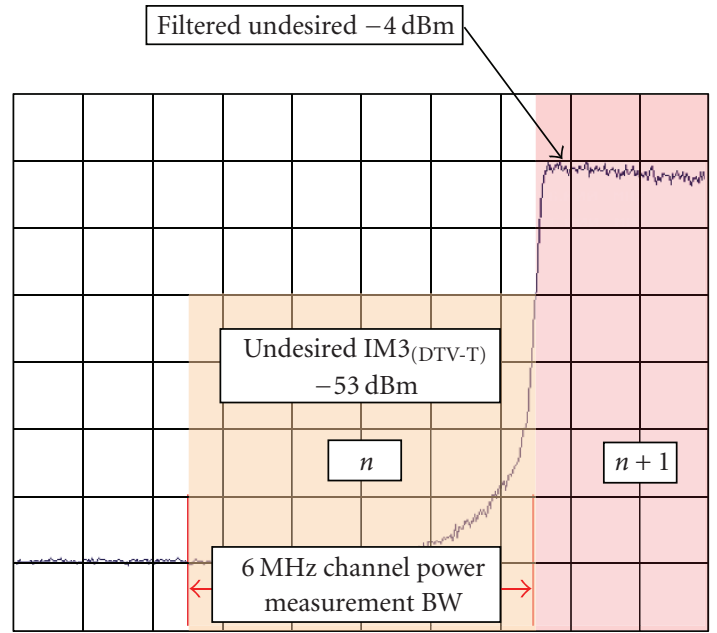

(d)

Figure 10: (a) $n=-28 \mathrm{dBm}$; undesired signal at $n-1$; minimum $\mathrm{IM}_{3 \text { (DTV-T) }}$ configuration (b) $n=-28 \mathrm{dBm}$; undesired signal at $n+$ 1 ; minimum $\mathrm{IM}_{3 \text { (DTV-T) }}$ configuration (c) $\mathrm{IM}_{3(\mathrm{DTV}-\mathrm{T})}$ level present in desired channel $n$. Undesired signal at $n-1$; Minimum IM 3 (DTV-T) Configuration. (d) $\mathrm{IM}_{3 \text { (DTV-T) }}$ Level Present in Desired Channel $n$. Undesired Signal at $n+1$; Minimum IM (DTV-T) $_{\text {configuration. }}$

generate considerably higher levels of $\mathrm{IM}_{3 \text { (DTV-T) }}$ interference in the adjacent desired channel bandwidth than in previous test with the same $-53 \mathrm{dBm} / 6 \mathrm{MHz}$ desired signal used in the previous test. Adjacent channel undesired signal levels required to degrade the $-53 \mathrm{dBm}$ desired channel to TOV are indicated in Table 3(b). Spectrum plots representative of a selection of Table 3(b) measurements are contained in Figures 9(a)-9(d).

The desired channel power level was increased to $-28 \mathrm{dBm}$ measured in a $6 \mathrm{MHz}$ bandwidth for the next receiver test. Channel $31(572-578 \mathrm{MHz})$ was again selected as the desired frequency. The ATSC signal was created using the KUWSDET 8VSB modulator and a looping HDTV MPEG-2 transport stream as in the preceding tests. The filtered undesired OFDM signal was configured to generate minimal levels of $\mathrm{IM}_{3 \text { (DTV-T) }}$ interference in the adjacent desired channel bandwidth, while maintaining operation within the region of the $1 \mathrm{~dB}$ compression point (P1dB) of amplifier A2. Adjacent channel undesired signal levels required to degrade the $-28 \mathrm{dBm}$ desired channel to TOV are indicated in Table 4(a). Example data from the measurement technique reference [18] is again included for comparison purposes, and spectrum plots representative of a selection of Table 3 measurements are contained in Figures 10(a)-10(d).

The same $-28 \mathrm{dBm}$ desired signal used in the preceding test was also used for the final receiver test. For this test, the undesired signal was again configured to produce significant levels of IM $_{3 \text { (DTV-T) }}$ interference. Adjacent channelundesired signal levels required to degrade the $-28 \mathrm{dBm}$ 


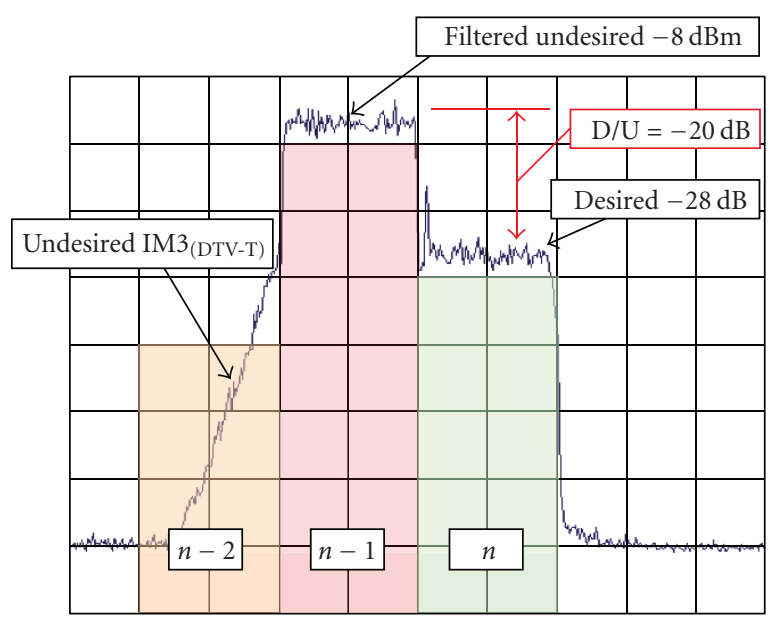

(a)

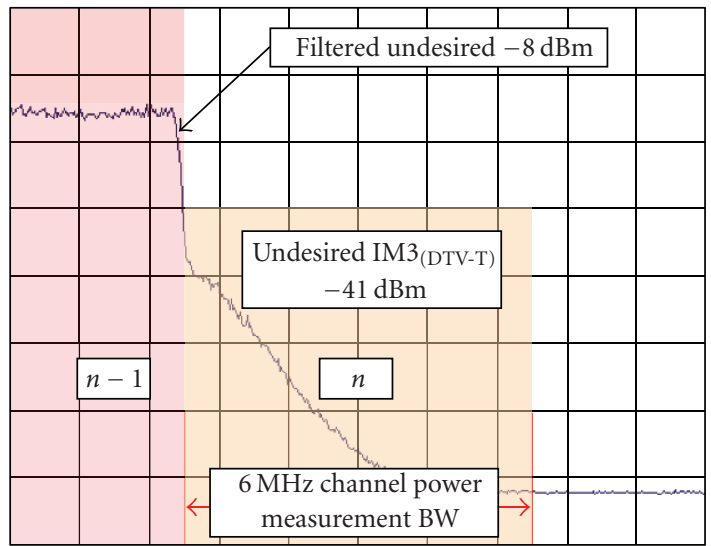

(c)

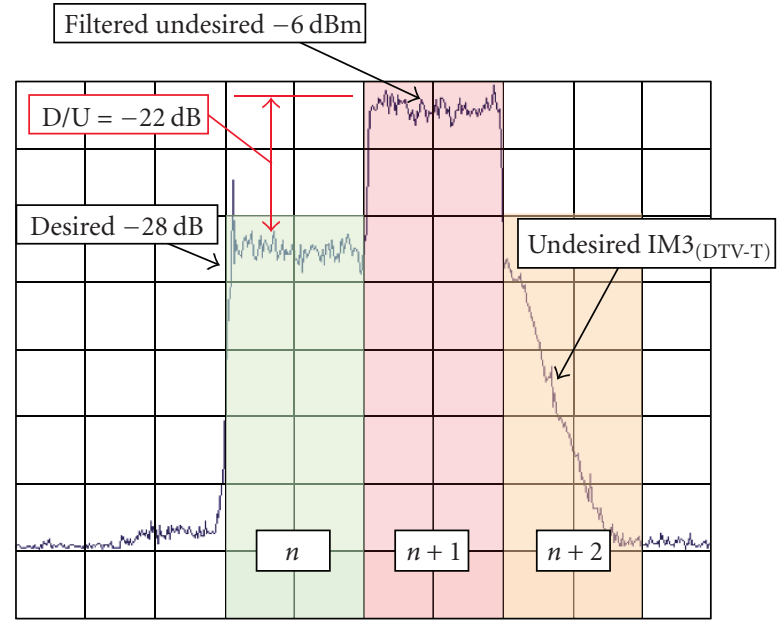

(b)

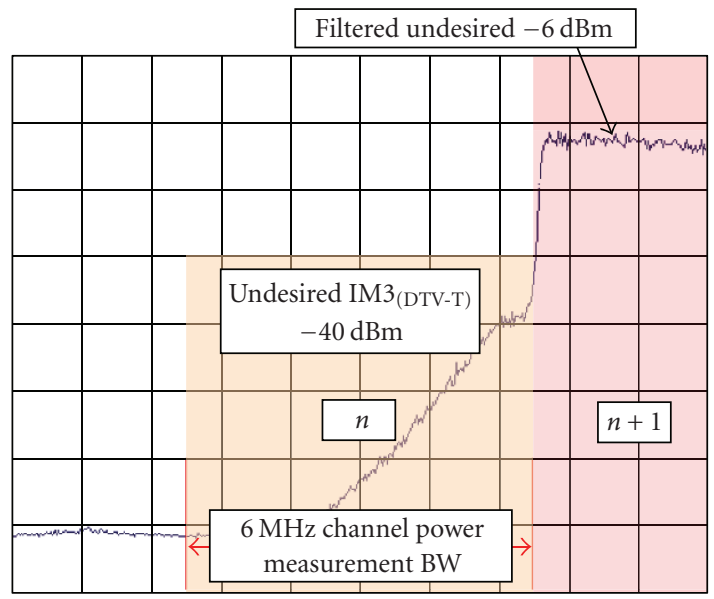

(d)

Figure 11: (a) $n=-28 \mathrm{dBm}$; Undesired signal at $n-1$; significant $\mathrm{IM}_{3 \text { (DTV) }}$ configuration (b) $n=-28 \mathrm{dBm}$; undesired signal at $n+1$;

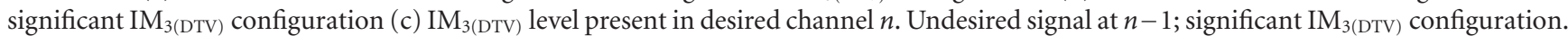
(d) $\mathrm{IM}_{3 \text { (DTV) }}$ level present in desired channel $n$. Undesired signal at $n+1$; significant $\mathrm{IM}_{3 \text { (DTV) }}$ configuration.

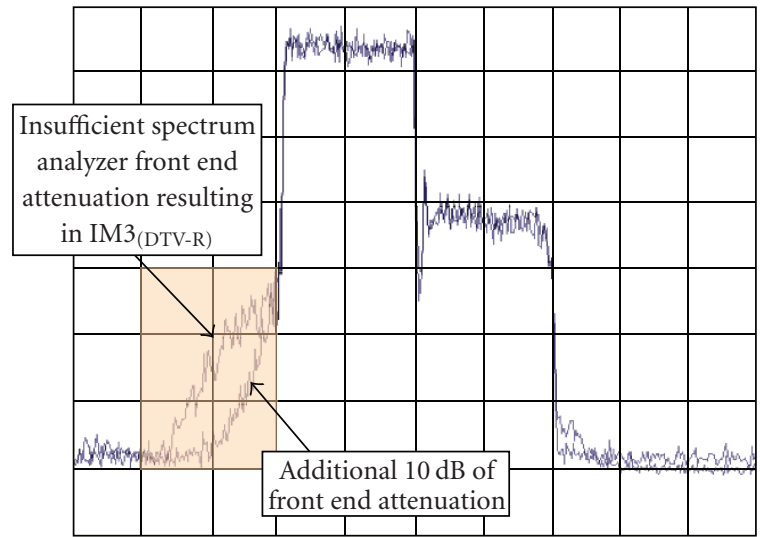

FIGURE 12: Example of $\mathrm{IM}_{3 \text { (DTV-R) }}$ using an improperly configured spectrum analyzer. desired channel to TOV are indicated in Table 4(b). Spectrum plots representative of a selection of Table 4 measurements are contained in Figures 11(a)-11(d).

5.3. Receiver-Generated Intermodulation Products. Direct spectrum analyzer measurement of receiver-generated intermodulation products $\mathrm{IM}_{3 \text { (DTV-R) }}$ was not covered in scope of this report, due to the necessity of receiver disassembly and measurement port insertion. Future investigations may include such an analysis. However, through the use of a purposely misconfigured spectrum analyzer, an effort has been made to illustrate $\mathrm{IM}_{3 \text { (DTV-R) }}$, as shown in Figure 12. The analyzer display content was first captured with the internal RF input attenuator properly configured, then with the same signal input levels, the analyzer attenuator setting 
TABLE 3: (a) Desired channel power $=-53 \mathrm{dBm} / 6 \mathrm{MHz}$; undesired signal with minimum $\mathrm{IM}_{3(\mathrm{DTV})}$; (b) desired channel power $=$ $-53 \mathrm{dBm} / 6 \mathrm{MHz}$; undesired signal with significant $\mathrm{IM}_{3(\mathrm{DTV})}$.

(a)

\begin{tabular}{|c|c|c|c|c|c|c|c|c|}
\hline \multirow[b]{2}{*}{ Receiver } & \multicolumn{3}{|c|}{$\begin{array}{l}n-1 \text { filtered undesired } \\
(\mathrm{dBm} / 6 \mathrm{MHz})\end{array}$} & \multirow[b]{2}{*}{$\begin{array}{l}\mathrm{D} / \mathrm{U} \\
(\mathrm{dB})\end{array}$} & \multicolumn{3}{|c|}{$\begin{array}{c}n+1 \text { filtered undesired } \\
(\mathrm{dBm} / 6 \mathrm{MHz})\end{array}$} & \multirow[b]{2}{*}{$\begin{array}{l}\mathrm{D} / \mathrm{U} \\
(\mathrm{dB})\end{array}$} \\
\hline & $\begin{array}{c}n-1 \\
\mathrm{CH} 30\end{array}$ & $\begin{array}{c}\mathrm{IM}_{3(\mathrm{DTV})} \\
\mathrm{CH} 31\end{array}$ & IP3DTV & & $\begin{array}{c}n+1 \\
\mathrm{CH} 32\end{array}$ & $\begin{array}{l}\mathrm{IM}_{3(\mathrm{DTV})} \\
\mathrm{CH} 31\end{array}$ & $\mathrm{IP}_{3(\mathrm{DTV})}$ & \\
\hline 1 (1999 model year set-top) & -24 & -67 & -2.5 & -29 & -19 & -66 & 4.5 & -34 \\
\hline 2 (32” LCD DTV) & -16 & -60 & 6 & -37 & -14 & -62 & 10 & -39 \\
\hline 3 (Low cost set-top) & -17 & -61 & 5 & -36 & -19 & -67 & 5 & -34 \\
\hline ATSC A/74 & -20 & & & -33 & -20 & & & -33 \\
\hline \multirow{4}{*}{\multicolumn{2}{|c|}{$\begin{array}{l}\text { Rhodes-sgrignoli } \\
\mathrm{IM}_{3 \text { (DTV) example }} \\
\text { (Figure 4; "Interference Mitigation for } \\
\text { Improved DTV Reception") }\end{array}$}} & & & & $n+1$ & $\mathrm{IM}_{3(\mathrm{DTV})}$ & $\mathrm{IP}_{3(\mathrm{DTV})}$ & \\
\hline & & & & & -19.6 & -57.8 & -0.5 & \\
\hline & & \multirow{2}{*}{\multicolumn{3}{|c|}{$\begin{array}{l}\text { Levels required to degrade } \\
\text { desired channel to TOV }\end{array}$}} & & & & \\
\hline & & & & & & & & \\
\hline
\end{tabular}

(b)

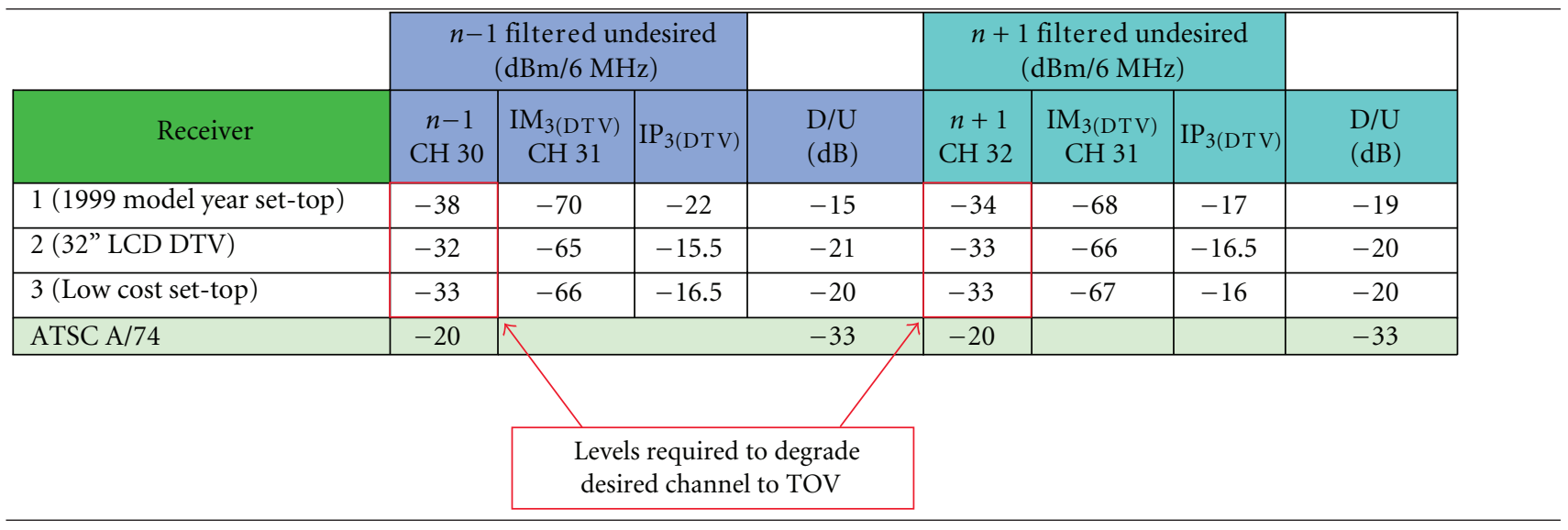

was manually reduced $10 \mathrm{~dB}$, resulting in the overload of one or more analyzer front end components. The goal of this simple demonstration is to show that not only can transmiter nonlinearities causes interference but an improperly configured receiver can also result in significant interference.

\section{Conclusion}

In this article, we have presented a feasibility study of secondary transmissions into the unused TV spectrum and have presented the observed effects of a single interfering secondary transmission on a selection of digital television receivers. The results indicate that carefully implemented secondary use of open channel bandwidth immediately adjacent to a licensed digital television transmission is a viable practice, given the expectation that WSD designs will place an emphasis on the protection of television broadcasts.

Device design challenges specific to white space operation include RF power amplifier linearity, signal filtering implementation, development of suitable cognitive properties, and refinement of adaptive capabilities to provide the maximum amount of protection to DTV broadcasts. Focusing research and development on these challenges will help to ensure the successful coexistence of primary and secondary users in the television spectrum.

\section{Acknowledgments}

The authors dedicate this work to the memory of their colleague and mentor, James A. "Jim" Roberts. His impressive 
TABle 4: (a) Desired channel power $=-28 \mathrm{dBm} / 6 \mathrm{MHz}$; minimum undesired signal $\mathrm{IM}_{3(\mathrm{DTV}-\mathrm{T})}$; (b) desired channel power $=$ $-28 \mathrm{dBm} / 6 \mathrm{MHz}$; significant undesired signal $\mathrm{IM}_{3(\mathrm{DTV}-\mathrm{T})}$.

(a)

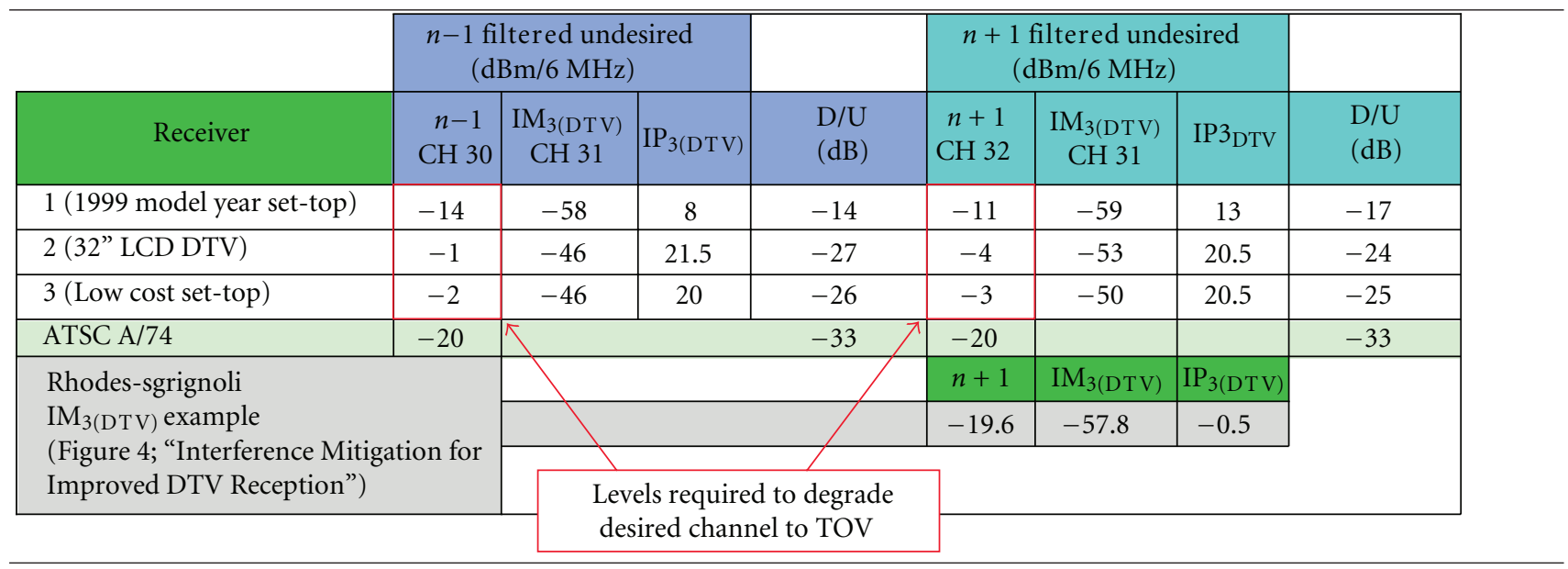

(b)

\begin{tabular}{|c|c|c|c|c|c|c|c|c|}
\hline \multirow[b]{2}{*}{ Receiver } & \multicolumn{3}{|c|}{$\begin{array}{l}-1 \text { filtered undesired } \\
(\mathrm{dBm} / 6 \mathrm{MHz})\end{array}$} & \multirow[b]{2}{*}{$\begin{array}{l}\mathrm{D} / \mathrm{U} \\
(\mathrm{dB})\end{array}$} & \multicolumn{3}{|c|}{$\begin{array}{c}n+1 \text { filtered undesired } \\
(\mathrm{dBm} / 6 \mathrm{MHz})\end{array}$} & \multirow[b]{2}{*}{$\begin{array}{l}\mathrm{D} / \mathrm{U} \\
(\mathrm{dB})\end{array}$} \\
\hline & $\begin{array}{c}n-1 \\
\mathrm{CH} 30\end{array}$ & $\begin{array}{l}\mathrm{IM}_{3(\mathrm{DTV})} \\
\mathrm{CH} 31\end{array}$ & $\mathrm{IP}_{3(\mathrm{DTV})}$ & & $\begin{array}{c}n+1 \\
\mathrm{CH} 32\end{array}$ & $\begin{array}{l}\mathrm{IM}_{3(\mathrm{DTV})} \\
\text { CH } 31\end{array}$ & IP3DTV & \\
\hline 1 (1999 model year set-top) & -15 & -48 & 1.5 & -13 & -11 & -45 & 6 & -17 \\
\hline $2(32 ”$ LCD DTV $)$ & -8 & -41 & 8.5 & -20 & -6 & -40 & 11 & -22 \\
\hline 3 (Low cost set-top) & -8 & -41 & 8.5 & -20 & -9 & -43 & 8 & -19 \\
\hline ATSC A/74 & -20 & & & -33 & -20 & & & -33 \\
\hline & & $\begin{array}{c}\text { Levels } \\
\text { desire }\end{array}$ & $\begin{array}{l}\text { required to } \\
\text { ed channel t }\end{array}$ & $\begin{array}{l}\text { grade } \\
\text { OV }\end{array}$ & & & & \\
\hline
\end{tabular}

career encompassed an array of accomplishments ranging from early work for the NASA Apollo program to President and Chief Operating Officer of the University of Kansas Center for Research. During his tenure at the University of Kansas, Jim's outstanding leadership and research skills touched all of them at KU; his direction and support served to elevate their individual efforts, resulting in numerous collective achievements. The work presented here is but one small example. Jim's legacy of talent, dedication, and friendship, combined with the manner in which he lived his tragically shortened life and bravely faced the end, stands as a shining example to follow. This work was supported by NSF grants ANI0230786, ANI-0335272, and grants from the New America Foundation.

\section{References}

[1] M. A. McHenry, "NSF spectrum occupancy measurementsproject summary," Shared Spectrum Company, August 2005.

[2] Federal Communications Commission, "Unlicensed operation in the TV broadcast bands," ET Docket No. 04-113, May 2004.

[3] “The XG Vision: Request For Comments, version 2.0," Tech. Rep., BBN Technologies.

[4] C. Cordeiro, K. Challapali, D. Birru, and N. Sai Shankar, "IEEE 802.22: the first worldwide wireless standard based on cognitive radios," in Proceedings of the 1st IEEE International Symposium on New Frontiers in Dynamic Spectrum Access Networks (DySPAN '05), pp. 328-337, Baltimore, Md, USA, November 2005.

[5] A. E. Leu, K. Steadman, M. McHenry, and J. Bates, "Ultra sensitive TV detector measurements," in Proceedings of the 1st 
IEEE International Symposium on New Frontiers in Dynamic Spectrum Access Networks (DySPAN '05), pp. 30-36, Baltimore, Md, USA, November 2005.

[6] E. Visotsky, S. Kuffher, and R. Peterson, "On collaborative detection of TV transmissions in support of dynamic spectrum sharing," in Proceedings of the 1st IEEE International Symposium on New Frontiers in Dynamic Spectrum Access Networks (DySPAN '05), pp. 338-345, Baltimore, Md, USA, November 2005.

[7] B. Wild and K. Ramchandran, "Detecting primary receivers for cognitive radio applications," in Proceedings of the 1st IEEE International Symposium on New Frontiers in Dynamic Spectrum Access Networks (DySPAN '05), pp. 124-130, Baltimore, Md, USA, November 2005.

[8] M. McHenry, "The probe spectrum access method," in Proceedings of the 1st IEEE International Symposium on New Frontiers in Dynamic Spectrum Access Networks (DySPAN '05), pp. 346-351, Baltimore, Md, USA, November 2005.

[9] V. R. Petty, R. Rajbanshi, D. Datla, et al., "Feasibility of dynamic spectrum access in underutilized television bands," in Proceedings of the 2nd IEEE International Symposium on New Frontiers in Dynamic Spectrum Access Networks (DySPAN '07), pp. 331-339, Dublin, Ireland, April 2007.

[10] American Federation of Musicians, "Comments in response to ET docket no. 04-186," October 2006.

[11] Wireless Internet Service Provider's Association, "Comments in response to ET docket no. 04-186," March 2006.

[12] R. Rajbanshi, A. M. Wyglinski, and G. J. Minden, "Adaptivemode peak-to-average power ratio reduction algorithm for OFDM-based cognitive radio," in Proceedings of the 64th IEEE Vehicular Technology Conference (VTC '06), pp. 1350-1354, Montreal, Canada, September 2006.

[13] S. B. R. Cabric and D. Mishra, "Implementation issues in spectrum sensing for cognitive radios," in Proceedings of the 38th Asilomar Conference on Signals, Systems and Computers, vol. 1, pp. 772-776, Pacific Grove, Calif, USA, November 2004.

[14] C. W. Rhodes, "Interference between television signals due to intermodulation in receiver front-ends," IEEE Transactions on Broadcasting, vol. 51, no. 1, pp. 31-37, 2005.

[15] "H.R.2015-Balanced Budget Act of 1997, Title III-Communications and Spectrum Allocations Provisions," http:// thomas.loc.gov/cgi-bin/query/F?c105:1:./temp/ c105LvLW HQ:e21719:.

[16] T. X. Brown, "An analysis of unlicensed device operation in licensed broadcast service bands," in Proceedings of the 1st IEEE International Symposium on New Frontiers in Dynamic Spectrum Access Networks (DySPAN '05), pp. 11-29, Baltimore, Md, USA, November 2005.

[17] D. Prendergast, M. Guillet, B. Caron, et al., "The effects of public safety mobile systems operations (in TV channels 63/68) on DTV and NTSC broadcasting," IEEE Transactions on Broadcasting, vol. 51, no. 1, pp. 43-50, 2005.

[18] C. W. Rhodes and G. J. Sgrignoli, "Interference mitigation for improved DTV reception," IEEE Transactions on Consumer Electronics, vol. 51, no. 2, pp. 463-470, 2005. 